$$
\begin{gathered}
\text { 허혈성 대장염의 임상 양상 비교: } \\
\text { 나이, 변비나 과민성 장 증후군 동반 여부에 따라 }
\end{gathered}
$$

전남대학교 의과대학 내과학교실, ${ }^{1}$ 전남대학교 의과학연구소

진남철 · 김연주 · 송영아 · 윤경원 · 박선영 · 조성범 · 이완식 ${ }^{1} \cdot$ 박창환 $^{1} \cdot$ 김현수 $^{1 *} \cdot$ 최성규 $\cdot$ 유종선 ${ }^{1}$

\title{
Clinical Features of Ischemic Colitis: Related to Age, Constipation, Irritable Bowel Syndrome
}

\author{
Nam-Chul Jin, Yeon-Ju Kim, Young-A Song, Kyung-Won Yoon, Sun-Young Park, Sung-Bum Cho, \\ Wan-Sik Lee ${ }^{1}$, Chang-Hwan Park ${ }^{1}$, Hyun-Soo Kim ${ }^{1 *}$, Sung-Kyu Choi ${ }^{1}$ and Jong-Sun Rew ${ }^{1}$ \\ Department of Internal Medicine, Chonnam National University Medical School, \\ ${ }^{1}$ Chonnam National University Research Institute of Medical Sciences, Gwangiu, Korea
}

\begin{abstract}
Ischemic colitis $(\mathrm{IC})$ is a frequent disorder in older person but it is usually self-limiting disease responding to conservative treatment. Recently, incidence of IC increase in gradual at broad range of age, especially to young age, relatively. The aims of this study are to evaluate clinical characteristics of patients with IC treated in Chonnam National University Hospital (CNUH). Between January 2000 and May 2007 in CNUH, 67 patients (30 males, 37 females) with IC were enrolled. We compared clinical features between young and elderly, group with IC accompanied with constipation, irritable bowel syndrome (IBS), or not. Among the $67 \mathrm{IC}$ patients, most patients $(79.1 \%)$ are older than fifty years and suffer from abdominal pain $(71.6 \%)$, hematochezia $(59.7 \%)$ and diarrhea (38.8\%). Most of all are diagnosed through colonoscopy $(79.1 \%)$ or abdominal CT (65.6\%) and recovered by conservative treatment $(89.6 \%)$. Risk factors for IC are atherosclerotic vascular diseases (56.7\%), vasoactive medicine (31.3\%), IBS (11.9\%) and constipation (13.4\%). Older age with IC has more frequently associated with risk factors. At the comparison associated with IBS, 3 patients $(37.5 \%)$ with IBS and 4 patients $(6.8 \%)$ without IBS have surgery $(\mathrm{p}=0.008)$. At the comparison associated with constipation, 45 patients $(77.6 \%)$ without constipation and 3 patients $(33.3 \%)$ with constipation have abdominal pain. The results suggest that the presence of IBS or constipation may not be associated with frequency or severity of IC. But more large scaled epidemiologic study was needed.
\end{abstract}

Keywords: Colitis; Ischemic; Constipation; Irritable bowel syndrome

게재결정: 2008년 11월 19일

*교신저자: 김현수, $501-757$, 전남대학교 의과대학 소화기내과학교실, Phone: 062-220-6200, FAX: 062-228-1330, E-mail: dshskim@jnu.ac.kr

\section{서 론}

허혈성 대장염은 대장을 침범하는 혈관성 질환 중 가장 흔한 형태이며 ${ }^{1-3}$ 전체 허혈성 위장관 질환의 약 $50 \sim 60 \%$ 를 차지한다. ${ }^{3}$ 허혈성 대장염은 심하지 않은 경우 복통과 설 
사와 같은 비특이적인 증상으로 대부분 병원을 찾기 전에 증상이 호전되는 경우가 많고, 병원을 찾는 경우에는 대개 혈성 설사와 복통이 주 증상이나 보존적 치료로 호전되는 경우가 많다. 허혈성 장 질환은 복통과 설사가 주 증상인 경 우 감염성이나 염증성 장 질환과 혼동되는 경우가 많아 감 별진단이 필요하다. ${ }^{2-6}$

허혈성 대장염의 원인은 대부분 확인하기 어려운 경우가 많 으나 ${ }^{1-4,7,8}$ 죽상경화성 혈관 질환(고혈압, 당뇨, 허혈성 심 질환, 고지혈증), 울혈성 심부전, 최근의 저혈압성 에피소드, 혈관에 작용하는 약물 복용력 등과 같은 선행 위험인자가 있으며,4 주로 고연령층에서 호발하고 젊은 연령층에서는 드문 질환으 로 알려져 있다. ${ }^{2-4,7-10}$ 하지만 최근 그 발생빈도가 점진적으로 증가하고 있는 추세로 비교적 젊은 연령층에서도 발생 빈도가 증가 하고 있으며 과민성 장 증후군의 변비 아형에서 허혈성 대장염이 호발한다는 보고가 있다. ${ }^{3,11-16}$

인구의 고령화 등으로 최근 허혈성 대장염이 증가하고 고혈 압 등 위험 인자가 증가하고 있는 상황에서 본원에서 진단된 허혈성 대장염의 임상 특징을 조사해 보고 이를 연령과 변비의 동반 여부에 따라 각각 두 군으로 나누어 임상적 특징을 알아 보고자 한다. 아울러 허혈성 대장염과 과민성 장 증후군의 아 형에 따른 상관 관계 규명을 통하여 향후 과민성 장 증후군의 치료와 합병증 발생 예방에 도움이 되고자 한다.

\section{대상 및 방법}

\section{1. 대상}

2000년 1월부터 2007년 5월까지 전남대학병원에서 임상 양상, 검사실 소견 및 영상학적 진단 등을 종합하여 허혈성 대장염으로 진단받은 67 명의 환자를 대상으로 하였다.

\section{2. 방법}

대상 환자의 나이, 성별, 동반질환, 증상, 신체 검진, 대장 내시경, 치료 및 임상 경과 등은 의무기록을 통해 후향적으 로 조사하였다. 대장 내시경은 내시경 의사가 내시경 당시 기술한 소견과 다른 의사의 재 판독을 토대로 의견이 일치 한 경우 진단하였고, 복부 전산화 단층 촬영은 영상 의학과 전문의의 판독 소견을 토대로 분석하였다.

\section{1. 허혈성 대장염}

허혈성 대장염의 진단은 다음과 같은 진단 기준에 기초하
여 이루어졌다. ${ }^{11}$ 복통과 혈성 설사와 같은 증상의 급성 발 현이 있고 궤양성 대장염이나 크론병과 같은 염증성 장 질 환의 병력과 증상 발현 직전에 항생제 등 약물 복용력이 없 으면서 대변 배양 검사에서 음성인 경우에 대장 내시경과 복부 전산화 단층 촬영에서 허혈성 대장염에 합당한 경우 허혈성 대장염으로 진단하였다.

\section{2. 과민성 장 증후군}

진단을 위하여 ROME III criteria를 기초로 설문지를 작 성하였고, 허혈성 대장염을 진단받은 67 명을 대상으로 직접 개별적인 전화 상담을 통해 과민성 장 증후군의 동반 여부 와 변비형, 설사형, 혼합형 등 그 아형을 분류하였다. ${ }^{17-19}$

\section{3. 비교 군 설정}

허혈성 대장염으로 진단된 67 명을 저연령군(<60세, 27 명)과 고연령군 $(\geq 60$ 세, 40 명)으로, 기저 질환으로 기능성 변비 동반군(변비형 과민성 장 증후군 환자와 만성 변비 환 자, 9명)과 비동반군(비변비형 과민성 장 증후군 환자 포함, 58 명)으로, 그리고 과민성 장 증후군 동반군과 비동반군으 로 각각 두 그룹으로 나누어 임상 양상을 비교하였다.

죽상경화성 혈관질환을 진단하기 위하여 동맥 경화도 검 사와 같은 객관적인 진단 검사를 시행하지 않았으나 고혈압, 당뇨, 허혈성 심질환, 고지혈증과 같은 질환을 동반하고 있 는 경우 죽상경화성 혈관질환으로 임상적 추정 진단하였다.

\section{3. 통계 분석}

모든 통계 분석은 SPSS (Version 15.0, SPSS Inc., Chicago, IL)을 이용하여 실행하였고 두 그룹 간의 비교는 Chisquared tests를 이용하였다. p값이 0.05 미만일 때 통계적 으로 유의한 것으로 하였다.

\section{결 과}

\section{1. 특성}

허혈성 대장염으로 진단된 67 명의 연령 분포는 30 대 이 하에서 5명(7.5\%), 40 대에서 5명(7.5\%), 50 대에서 18 명 (26.9\%), 60대에서 18명(26.9\%), 70대에서 17명(25.4\%), 80 대 이상에서 4 명 $(6.0 \%)$ 으로 50 대에서 70 대까지가 53 명 으로 전체의 $79.1 \%$ 를 차지하였으며, 평균 연령은 $62.18 \pm$ 14.75세였고 중앙값은 64세였다. 남녀 성비는 남자 30명 
(44.8\%), 여자 37명(55.2\%)이었다.

주 증상은 복통(48명, $71.61 \%$ ), 하혈(40명, 59.7\%), 설 사(26명, $38.8 \%)$ 순으로 분석되었으며 바륨 관장을 통해 3 명(4.5\%), 대장 내시경을 통해 53명(79.1\%), 복부 전산화 단층 촬영을 통해 42 명(65.6\%)을 진단하였다.

보존적 치료는 60명(89.6\%), 수술적 치료는 7명(10.4\%) 에서 시행되었으며 이들 중 64 명 $(95.5 \%)$ 은 회복되었고, 3 명 $(4.5 \%)$ 은 타 병원으로 전원되었으며 사망한 환자는 없었 다(Table 1).

Table 1. Clinical features of ischemic colitis patients*

\begin{tabular}{|c|c|}
\hline Clinical parameters & Case (\%) \\
\hline \multicolumn{2}{|l|}{ Age(years) } \\
\hline$\sim 40$ & $5(7.5)$ \\
\hline $41 \sim 50$ & $5(7.5)$ \\
\hline $51 \sim 60$ & $18(26.9)$ \\
\hline $61 \sim 70$ & $18(26.9)$ \\
\hline $71 \sim 80$ & $17(25.4)$ \\
\hline $81 \sim$ & $4(6.0)$ \\
\hline \multicolumn{2}{|l|}{ Sex } \\
\hline Male & $30(44.8)$ \\
\hline Female & $37(55.2)$ \\
\hline \multicolumn{2}{|l|}{ Risk factor } \\
\hline Atherosclerotic vascular disease & $38(56.7)$ \\
\hline Hypertension & $19(28.4)$ \\
\hline Diabetes mellitus & $13(19.4)$ \\
\hline Ischemic heart disease & $4(6.0)$ \\
\hline Old cerebrovascular accident & $4(6.0)$ \\
\hline Congestive heart failure & $1(1.5)$ \\
\hline Recent hypotensive episode & $3(4.5)$ \\
\hline Vasoactive medication & $21(31.3)$ \\
\hline \multicolumn{2}{|l|}{ Symptom } \\
\hline Abdominal pain & $48(71.6)$ \\
\hline Hematochezia & $40(59.7)$ \\
\hline Diarrhea & $26(38.8)$ \\
\hline \multicolumn{2}{|l|}{ Diagnostic modality } \\
\hline Barium enema & $3(4.5)$ \\
\hline Colonoscopy & $53(79.1)$ \\
\hline Abdominal CT & $42(65.6)$ \\
\hline \multicolumn{2}{|l|}{ Therapeutic modality } \\
\hline Conservative treatment & $60(89.6)$ \\
\hline Operation & $7(10.4)$ \\
\hline Irritable bowel syndrome & $8(11.9)$ \\
\hline Functional constipation & $6(9.0)$ \\
\hline Constipation $^{\dagger}$ & $9(13.4)$ \\
\hline \multicolumn{2}{|l|}{ Hospital course } \\
\hline Recovery & $64(95.5)$ \\
\hline Death & $0(0.0)$ \\
\hline Transfer to other clinics & $3(4.5)$ \\
\hline
\end{tabular}

${ }^{*}$ Patients with ischemic colitis are $67 ;{ }^{\dagger}$ Constipation includes constipation type of irritable bowel syndrome and functional constipation.

\section{2. 동반 질환-위험 인자}

허혈성 대장염의 발생과 관련하여 고혈압, 당뇨병, 허혈성 심질환, 뇌혈관장애와 같은 죽상경화성 혈관질환이 38 명 (56.7\%), 혈관에 작용하는 약물 복용력도 21명(31.3\%)으로 나타났다. 죽상경화성 혈관질환 중 고혈압은 19명(28.4\%), 당뇨병은 13명(19.4\%), 허혈성 심질환은 4명(6.0\%), 뇌혈 관장애는 4명(6.0\%)을 각각 차지하였다(Table 1).

그 외 과민성 장 증후군은 총 8 명 $(11.9 \%)$ 에서 동반되었 으며 아형 별로는 변비형이 3명(37.5\%-남성 33.3\%), 설사 형이 4명(50\%-남성 50\%), 혼합형이 1명(12.5\%-남성 0\%) 이었으며, 변비형 과민성 장 증후군의 3 명과 함께 기능성 변비 6명(9.0\%)을 포함하여 9명(13.4\%)이 변비를 호소하 였다(Table 2).

\section{3. 연령에 따른 임상 양상 비교}

저연령군(60세 미만, 27명)은 평균 연령이 $48.44 \pm 12.20$ 세 이었고 남녀 성별에서는 남자가 13명(48.1\%), 여자가 15 명(51.9\%)이었다. 고연령군(60세 이상, 40 명)은 평균 연 령이 $71.45 \pm 7.08$ 세였고 남녀 성별에서는 남자가 17 명(42.5\%), 여자가 23명(57.5\%)으로 두 군 간의 남녀 성별에서 통계적 으로 유의한 차이는 없었다.

허혈성 대장염의 발생과 관련하여 죽상경화성 혈관 질환 은 저연령군에서 9명(33.3\%), 고연령군에서 29명(72.5\%) 으로 고연령군에서 통계적으로 유의하게 죽상경화성 혈관 질환의 동반이 많았다 $(\mathrm{p}<0.02)$. 죽상경화증과 관련된 개별 질환의 경우 고혈압이 저연령군에서 0 명, 고연령군에서 19 명 $(47.5 \%)$ 으로 통계적 유의한 차이를 보였으나 $(\mathrm{p}<0.02)$ 당뇨병, 허혈성 심 질환, 뇌혈관 장애는 두 군 간의 유의한 차이는 없었다. 혈관에 작용하는 약물 복용력은 저연령 군에 서 0명, 고연령 군에서 21명(52.5\%)으로 통계적으로 유의 한 차이를 보였다 $(\mathrm{p}<0.02)$.

변비의 경우 변비형 과민성 장 증후군과 기능성 변비를

Table 2. Irritable bowel syndrome ${ }^{\star}$ and its subtype among Ischemic colitis

\begin{tabular}{lccc}
\hline \multirow{2}{*}{ Sex } & \multicolumn{3}{c}{ Type } \\
\cline { 2 - 4 } & Constipation & Diarrhea & Mixed \\
\hline Male & 1 & 2 & 0 \\
Female & 2 & 2 & 1 \\
Total & 3 & 4 & 1 \\
\hline
\end{tabular}

*Patients with IBS among IC patients are 8 . 
포함하여 고연령군에서 8명(20.0\%), 저연령군에서 1명(3.7\%) 으로 고연령 군에서 높은 빈도를 보였으나 통계적으로 유의 한 차이가 없었으며, 또한 임상 증상, 질환의 중증도, 고혈 압, 허혈성 심질환을 제외한 기저질환, 임상 경과 등도 두 군 간의 통계적인 유의한 차이는 없었다(Table 3).

\section{4. 과민성 장 증후군 동반 여부에 따른 임상 양상 비교}

과민성 장 증후군을 동반한 군은 8 명으로 변비형이 3 명 $(37.5 \%)$, 설사형이 4 명 $(50 \%)$, 혼합형이 1 명 $(12.5 \%)$ 이며, 평 균 연령이 $65.00 \pm 10.66$ 세, 남녀 성별은 남자가 3 명 $(37.5 \%)$,

Table 3. Clinical features of ischemic colitis patients: comparison between young and elderly groups

\begin{tabular}{|c|c|c|c|}
\hline Clinical parameters & $\begin{array}{c}\text { Young group }{ }^{\dagger} \\
\text { case }(\%)\end{array}$ & $\begin{array}{c}\text { Elderly group } \\
\text { case }(\%)\end{array}$ & $p$ value \\
\hline \multicolumn{4}{|l|}{ Age } \\
\hline$\sim 40$ & $5(16.6)$ & $0(0.0)$ & \\
\hline $41 \sim 50$ & $5(16.6)$ & $0(0.0)$ & \\
\hline $51 \sim 60$ & $18(66.7)$ & $0(0.0)$ & \\
\hline $61 \sim 70$ & $0(0.0)$ & $19(47.5)$ & \\
\hline $71 \sim 80$ & $0(0.0)$ & $17(42.5)$ & \\
\hline $81 \sim$ & $0(0.0)$ & $4(10.0)$ & \\
\hline \multicolumn{4}{|l|}{ Sex } \\
\hline Male & $13(48.1)$ & $17(42.5)$ & 0.648 \\
\hline Female & $14(51.9)$ & $23(57.5)$ & \\
\hline \multicolumn{4}{|l|}{ Risk factor } \\
\hline $\begin{array}{l}\text { Atherosclerotic } \\
\text { vascular disease }\end{array}$ & $9(33.3)$ & $29(72.5)$ & 0.020 \\
\hline Hypertension & $0(0.0)$ & $19(47.5)$ & 0.000 \\
\hline Diabetes mellitus & $4(14.8)$ & $9(22.5)$ & 0.435 \\
\hline $\begin{array}{l}\text { Ischemic heart } \\
\text { disease }\end{array}$ & $0(0.0)$ & $4(10.0)$ & 0.090 \\
\hline $\begin{array}{l}\text { Old cerebrovascular } \\
\text { accident }\end{array}$ & $1(3.7)$ & $3(7.5)$ & 0.520 \\
\hline $\begin{array}{l}\text { Congestive heart } \\
\text { failure }\end{array}$ & $0(0.0)$ & $1(2.5)$ & 0.417 \\
\hline $\begin{array}{l}\text { Recent hypotensive } \\
\text { episode }\end{array}$ & $2(7.4)$ & $1(2.5)$ & 0.341 \\
\hline Vasoactive medication & $0(0.0)$ & $21(52.5)$ & 0.000 \\
\hline \multicolumn{4}{|l|}{ Symptom } \\
\hline Abdominal pain & $20(74.1)$ & $28(70.0)$ & 0.717 \\
\hline Hematochezia & $13(48.1)$ & $27(67.5)$ & 0.113 \\
\hline Diarrhea & $8(29.6)$ & $18(45.0)$ & 0.205 \\
\hline \multicolumn{4}{|l|}{ Therapeutic modality } \\
\hline Conservative treatment & $22(81.5)$ & $38(95.0)$ & 0.076 \\
\hline Operation & $5(18.5)$ & $2(5.0)$ & 0.076 \\
\hline Irritable bowel syndrome & $3(11.1)$ & $5(12.5)$ & 0.863 \\
\hline Functional constipation & $1(3.7)$ & $5(12.5)$ & 0.216 \\
\hline Constipation* & $1(3.7)$ & $8(20.0)$ & 0.055 \\
\hline
\end{tabular}

${ }^{*}$ Constipation include constipation type of irritable bowel syndrome and functional constipation; ${ }^{\dagger}$ Patients of young group are less than 60 year old $(n=27)$; ${ }^{\ddagger}$ Patients of elderly group are more than 60 year old $(n=40)$.
여자가 5명 $(62.5 \%)$ 이었다(Table 2,4$)$. 과민성 장 증후군을 동반하지 않은 군은 59명으로 평균 연령이 $61.80 \pm 15.25$ 세 이며, 남녀 성별은 남자가 27명(45.8\%), 여자가 32명(54.2\%) 이었다(Table 4).

치료에서 과민성 장 증후군을 동반한 군은 보존적 치료를 5명(62.5\%), 수술적 치료를 3명(37.5\%)에서 시행하였으며, 동반하지 않은 군은 보존적 치료를 55명(91.7\%) 수술적 치 료를 4명 $(6.8 \%)$ 에서 시행하여 과민성 장 증후군을 동반한 군에서 수술적 치료가 통계적으로 많았다 $(\mathrm{p}<0.05)$. 그 외 허혈성 대장염의 위험인자, 증상, 치료 방법 및 임상 경과에 서 두 군 간의 통계적으로 유의한 차이는 없었다.

\section{5. 변비 동반 여부에 따른 임상 양상 비교}

변비를 동반한 군은 기능성 변비를 동반한 6명과 변비형 과민성 장 증후군 동반 3 명을 포함하여 총 9명으로 평균 연

Table 4. Clinical features of ischemic colitis patients: comparison between IBS (irritable bowel syndrome) and non-IBS groups

\begin{tabular}{|c|c|c|c|}
\hline Clinical parameters & $\begin{array}{l}\text { IBS group* } \\
\text { case }(\%)\end{array}$ & $\begin{array}{c}\text { Non-IBS group } \\
\text { case }(\%)\end{array}$ & $p$ value \\
\hline \multicolumn{4}{|l|}{ Age } \\
\hline$\sim 40$ & $0(0.0)$ & $5(8.5)$ & \\
\hline $41 \sim 50$ & $0(0.0)$ & $4(6.8)$ & \\
\hline $51 \sim 60$ & $3(37.5)$ & $15(25.4)$ & \\
\hline $61 \sim 70$ & $2(25.0)$ & $17(28.8)$ & \\
\hline $71 \sim 80$ & $3(37.5)$ & $14(23.7)$ & \\
\hline $81 \sim$ & $0(0.0)$ & $4(6.8)$ & \\
\hline \multicolumn{4}{|l|}{ Sex } \\
\hline Male & $3(37.5)$ & $27(45.8)$ & 0.659 \\
\hline Female & $5(62.5)$ & $32(54.2)$ & \\
\hline \multicolumn{4}{|l|}{ Risk factor } \\
\hline $\begin{array}{l}\text { Atherosclerotic } \\
\text { vascular disease }\end{array}$ & $4(50.0)$ & $34(57.6)$ & 0.683 \\
\hline Hypertension & $1(12.5)$ & $18(30.5)$ & 0.289 \\
\hline Diabetes mellitus & $1(12.5)$ & $12(20.3)$ & 0.599 \\
\hline Ischemic heart disease & $0(0.0)$ & $4(6.8)$ & 0.448 \\
\hline $\begin{array}{l}\text { Old cerebrovascular } \\
\text { accident }\end{array}$ & $0(0.0)$ & $4(6.8)$ & 0.448 \\
\hline Congestive heart failure & $0(0.0)$ & $1(1.7)$ & 0.708 \\
\hline $\begin{array}{l}\text { Recent hypotensive } \\
\text { episode }\end{array}$ & $0(0.0)$ & $3(5.1)$ & 0.514 \\
\hline Vasoactive medication & $1(12.5)$ & $20(33.9)$ & 0.221 \\
\hline \multicolumn{4}{|l|}{ Symptom } \\
\hline Abdominal pain & $6(75.0)$ & $42(71.2)$ & 0.822 \\
\hline Hematochezia & $3(37.5)$ & $37(62.7)$ & 0.172 \\
\hline Diarrhea & $3(37.5)$ & $23(39.0)$ & 0.936 \\
\hline \multicolumn{4}{|l|}{ Therapeutic modality } \\
\hline Conservative treatment & $5(62.5)$ & $55(91.7)$ & 0.008 \\
\hline Operation & $3(37.5)$ & $4(6.8)$ & 0.008 \\
\hline
\end{tabular}

${ }^{*}$ Patients with IBS among IC patients are $8 ;{ }^{\dagger}$ Patients without IBS among IC patients are 59 
Table 5. Clinical features of ischemic colitis patients: comparison between constipation* and non-constipation groups

\begin{tabular}{|c|c|c|c|}
\hline Clinical parameters & $\begin{array}{l}\text { Constipation }{ }^{\dagger} \\
\text { case }(\%)\end{array}$ & $\begin{array}{c}\text { Non-constipation }{ }^{\ddagger} \\
\text { case }(\%)\end{array}$ & $p$ value \\
\hline \multicolumn{4}{|l|}{ Age } \\
\hline$\sim 40$ & $0(0.0)$ & $5(8.6)$ & \\
\hline $41 \sim 50$ & $0(0.0)$ & $4(6.9)$ & \\
\hline $51 \sim 60$ & $1(11.1)$ & $17(29.3)$ & \\
\hline $61 \sim 70$ & $2(22.2)$ & $17(29.3)$ & \\
\hline $71 \sim 80$ & $6(66.7)$ & $11(19.0)$ & \\
\hline $81 \sim$ & $0(0.0)$ & $4(6.9)$ & \\
\hline \multicolumn{4}{|l|}{ Sex } \\
\hline Male & $4(44.4)$ & $26(44.8)$ & 0.983 \\
\hline Female & $5(55.6)$ & $32(55.2)$ & \\
\hline \multicolumn{4}{|l|}{ Risk factor } \\
\hline $\begin{array}{l}\text { Atherosclerotic } \\
\text { vascular disease }\end{array}$ & $5(55.6)$ & $33(56.9)$ & 0.940 \\
\hline Hypertension & $2(22.2)$ & $17(29.3)$ & 0.661 \\
\hline Diabetes mellitus & $2(22.2)$ & $11(19.0)$ & 0.818 \\
\hline Ischemic heart disease & $0(0.0)$ & $4(6.9)$ & 0.417 \\
\hline $\begin{array}{l}\text { Old cerebrovascular } \\
\text { accident }\end{array}$ & $0(0.0)$ & $4(6.9)$ & 0.417 \\
\hline Congestive heart failure & $0(0.0)$ & $1(1.8)$ & 0.689 \\
\hline $\begin{array}{l}\text { Recent hypotensive } \\
\text { episode }\end{array}$ & $0(0.0)$ & $3(5.2)$ & 0.485 \\
\hline Vasoactive medication & $2(2.2)$ & 19 (32.8) & 0.526 \\
\hline \multicolumn{4}{|l|}{ Symptom } \\
\hline Abdominal pain & $3(33.3)$ & $45(77.6)$ & 0.006 \\
\hline Hematochezia & $5(55.6)$ & $35(60.3)$ & 0.785 \\
\hline Diarrhea & $4(44.4)$ & $22(37.9)$ & 0.709 \\
\hline \multicolumn{4}{|l|}{ Therapeutic modality } \\
\hline Conservative treatment & $7(77.8)$ & $53(91.4)$ & 0.215 \\
\hline Operation & $2(22.2)$ & $5(8.6)$ & 0.215 \\
\hline
\end{tabular}

${ }^{*}$ Constipation include constipation type of irritable bowel syndrome and functional constipation; ${ }^{\dagger}$ Patients with constipation among IC patients are 9; ${ }^{\dagger}$ Patients without constipation among IC patients are 58.

령이 $72.33 \pm 7.34$ 세이며, 남녀 성비에서 남자가 4명 $44.4 \%)$ 여자가 5명(55.6\%)이었고, 변비를 동반하지 않은 군은 58 명으로 평균 연령이 $60.60 \pm 15.01$ 세이며, 남녀 성비에서 남 성이 26명(44.8\%) 여성이 32명(55.2\%)이었다.

임상 증상에서 변비를 동반한 군은 복통이 3 명 $(33.3 \%)$, 변비를 동반하지 않은 군은 45 명(77.6\%)으로 변비가 동반 되지 않은 군에서 복통이 통계적으로 유의하게 많았다 $(\mathrm{p}<$ 0.02). 그 외 양 군 간의 임상 양상 및 특성에 있어 통계적 으로 유의한 차이는 없었다(Table 5).

\section{고 찰}

인구의 고령화와 고혈압, 당뇨, 허혈성 심질환 등 허혈성
대장염과 연관성이 입증된 위험 인자가 증가되고 있는 시점 에서 허혈성 대장염으로 진단 및 치료를 받은 환자의 임상 특성을 파악하는 것은 향후 환자의 치료와 질병과 연관된 합병증의 예방에 있어서 중요한 일이다. 본 연구는 이런 문 제 인식에서 시작하여 본원에서 진단된 허혈성 대장염의 임 상 특성을 연령에 따라, 위험인자에 따라 비교 분석하였다.

대장 벽 내의 혈액 순환 장애는 대장 벽에 존재하는 동맥 의 혈관 내 혈전을 유발시키고, 형성된 혈전은 말단부의 혈 관 폐쇄를 가져와 허혈성 대장염이 유발된다는 것이 지금까 지 일반적으로 받아들여지고 있는 병인이다. 따라서 혈액 순 환 장애를 유발하는 죽상경화증과 이와 관련된 기저 질환은 허혈성 대장염의 발생에 있어 가장 중요한 위험인자 중 하 나이다. ${ }^{11}$

본 연구에서 허혈성 대장염으로 진단된 67 명은 저연령 군 (<60세, 27명)과 고연령 군( $\geq 60$ 세, 40 명)으로 두 그룹으 로 나누어 임상 양상을 비교한 결과 허혈성 대장염의 발생 과 관련하여 고혈압, 당뇨병, 허혈성 심 질환, 뇌 혈관 질환 과 같은 죽상경화성 혈관 질환과 혈관에 작용하는 약물 복 용력이 고연령 군에서 통계적으로 유의하게 높게 나타났으 며, 이것은 60 세 이상의 고연령 군에서 60 세 미만의 저연령 군에 비하여 허혈성 대장염의 발생과 관련된 선행 위험인자 의 동반 가능성이 더 높기 때문인 것으로 생각한다. ${ }^{3,4}$ 이전 연구 결과에 따르면 비의인성 원인에 의한 허혈성 대장염의 약 $90 \%$ 가 60 세 이상의 연령에서 발생하며, 60 세 미만의 연 령 군과 비교하여 허혈성 대장염 발생에 대한 승산비가 5.7 에 이른 것으로 보고되고 있다. ${ }^{20-22} 60$ 세 이상의 고연령 군 과 60 세 미만의 저연령 군 사이에 허혈성 대장염의 임상 양 상을 비교한 또 다른 연구 결과에 따르면 60 세 미만의 저연 령 군에서 변비, 과민성 장 증후군, 복부 수술 과거력의 빈 도가 높은 반면에 고연령 군에서는 죽상경화증과 관련된 고 혈압, 당뇨, 허혈성 심 질환과 같은 기저 질환의 빈도가 높 게 나타났다. ${ }^{8}$ 이는 본 연구에서 허혈성 대장염의 발생과 관 련하여 고혈압, 허혈성 심 질환과 같은 죽상경화성 혈관 질 환과 혈관에 작용하는 약물 복용력이 고연령 군에서 통계적 으로 유의하게 높게 나타난 점과 비슷한 결과이다. 하지만 다른 연구 결과와 달리 본 연구에서는 저 연령 군의 기능성 변비와 과민성 장 증후군의 빈도가 통계적으로 유의한 수준 으로 높게 나타나지 않았다. 다만 기능성 변비와 변비형 과 민성 장 증후군을 함께 고려 할 경우에 고연령 군에서 상대 적으로 높은 변비의 빈도를 보였다. 이는 고연령층에서 변비 가 호발하지만 본 연구의 허혈성 대장염에서 변비가 상대적 
으로 낮은 빈도를 보인 결과로 생각한다.

죽상경화증과 같은 혈관 요인 외에도 대장 벽 내의 혈액 순환에 장애를 유발할 수 있는 요인으로 대장 팽창과 대장 내 압력 상승과 같은 장 내 요인이 있다. 대장 팽창이나 대 장 내 압력 상승은 대장 벽 내 압력을 상승시키고 이로 인해 혈액 순환 장애가 유발되며 이러한 혈액 순환 장애는 죽상 경화성 혈관 질환과 같은 병인으로 허혈성 대장염을 유발 시킬 수 있다. 대장 팽창과 대장 내 압력 상승을 발생시킬 수 있는 장 내 요인에는 과민성 장 증후군이나 만성 변비가 있다. 본 연구에서 기저 질환으로 과민성 장 증후군 동반 군 과 비동반 군을 비교 분석한 결과 과민성 장 증후군을 동반 한 허혈성 대장염 군에서 동반하지 않은 군에 비하여 보존 적 치료보다는 수술이 필요한 경우가 통계적으로 유의하게 높게 나타났다. 이는 평소 과민성 장 증후군 증상이 만성적 으로 있어 병원을 늦게 방문하게 할 수 있을 것으로 생각하 나 좀 더 많은 증례에서 관찰 연구가 필요하다.

보존적 치료로 회복된 경증의 허혈성 대장염 군과 수술이 필요하거나 사망했던 중증의 허혈성 대장염 군으로 환자 군 을 분류한 후 양측의 임상 양상을 비교하였던 허혈성 대장 염의 중증도와 관련된 이전 연구에서 하혈이 없는 경우, 빈 맥, 복막 자극 증상, 빈혈, 저 나트륨 혈증이 나쁜 예후 인자 로 보고되었다. 하지만 본 연구에서 과민성 장 증후군의 동 반 유무와 하혈의 발생 빈도 사이에 통계적으로 유의한 차 이는 없었다. ${ }^{15}$ 다른 연구에 따르면 과민성 장 증후군이 있 는 환자에서 대조군에 비해 허혈성 대장염에 대한 비교 위 험도가 3.17 , 변비의 경우 2.78 로 높게 나타났다. ${ }^{3}$ 이는 대 규모 비교연구(comparative)를 통해 얻어진 결과로서 본 연 구와 같은 기술적 연구(descriptive study)에서는 장 측 요 인의 비교 위험도를 산출할 수 없다. 이러한 한계점으로 인 해 본 연구에서는 비교 위험도 산출 대신 장 측 요인을 가진 군과 그렇지 않은 군의 임상 양상의 차이를 확인하였다.

또 다른 장내 요인인 변비에 대하여 본 연구에서는 변비 를 동반한 군이 변비를 동반하지 않은 군에 비해 복통이 보 다 빈번하게 발생하였다는 점을 제외하고 양 군 간의 임상 양상 및 특성에 있어 통계적으로 유의한 차이는 없었다. 만 성 변비나 과민성 장 증후군을 갖는 환자 군에서 허혈성 대 장염의 발생 위험이 높다는 사실은 이전 연구에서 밝혀진 바이다. ${ }^{3,11}$ 따라서 과민성 장 증후군의 아형 중 변비 형이 다른 아형에 비해 상대적으로 허혈성 대장염의 발생 위험이 높다는 것을 추론할 수 있겠다. 본 연구에서는 허혈성 대장 염 환자 중 과민성 장 증후군으로 진단된 8 명의 환자를 아
형 별로 분류하여 분포를 확인하였으나 아형 별로 뚜렷한 분포 차이를 보이지 않았다. 하지만 표본 크기와 기술 통계 의 한계로 통계적 유의성은 부여하기 어렵다. 따라서 과민성 장 증후군의 아형 별 허혈성 대장염 발생 위험도 차이에 대 한 연구를 위해서는 코호트 연구(Cohort study)와 같은 비 교 연구가 이루어져야 하겠다.

\section{References}

1. Brandt LJ, Boley SJ. Colonic ischemia. Surg Clin North Am 1992;72: 203-29.

2. Lim YJ, Son HJ, Kang TW, Kim GC, Lee MS, Lee JH, et al. Clinical patterns and prognostic factors of ischemic colitis. Korean J Gastrointest Endosc 2001;22:76-82.

3. Suh DC, Kahler KH, Choi IS, Shin H, Kralstein J, Shetzliner M. Patients with irritable bowel syndrome or constipation have an increased risk for ischaemic colitis. Aliment Pharmacol Ther 25;681-92.

4. MacDonald PH. Ischemic colitis. Best Pract Res Clin Gastroenterol 2002;16:51-61.

5. MacDonald PH. Ischaemic colitis. Best Pract Res Clin Gastroenterol 2002;16:51-61.

6. Knudsen JF, Friedman B, Chen M, Goldwasser JE. Ischemic colitis and sumatriptan use. Arch Intern Med 1998;158:1946-8.

7. Toursarkissian B, Thompson RW. Ischemic colitis. Surg Clin North AM 1997;77:461-70.

8. Gomella LG, Gehrken GA, Hagihara PF, Flanigan RC. Ischemic colitis and immunosupression. An experimental model. Dis Colon Rectum 1986;29:99-101.

9. Miller WT, De Poto DW, Scholl HW, Raffensperger EC. Evanescent colitis in the young adult: a new entity? Radiology 1971;100:71-8.

10. Greenwald DA, Brandt LJ. Colonic ischemia. J Clin Gastroenterol 1998;27:122-8.

11. Gen T, Seiju H, Ken-ichi S, Hitoshi S, Chikako K, Teruyuki K. Evaluation of clinical features of ischemic colitis: comparison between young and elderly. Digestive Endoscopy 2005;17:123-30.

12. Cole AJ, Cook SF, Sands BE, Ajene AN, Miller DP, Walker AM. Occurrence of colon ischemia in relation to irritable bowel syndrome. Am J Gastroenterol 2004;99:486-91.

13. Walker AM, Bohn RL, Cali C, Cook SF, Ajene AN, Sands BE. Risk factors for colon ischemia. Am J Gastroenterol 2004;99:1333-7.

14. Suh DC, Kahler KH, Choi IS, Shin Hc, Kralstein J. Patients less than 65 years of age suffering from irritable bowel syndrome or constipation have a high risk of being diagnosed with ischemic colitis. American College of Gastroenterology Annual Meeting, October 29-November 2, 2005, Honolulu, Hawaii.

15. Añón R, Boscá MM, Sanchiz V, Tosca J, Almela P, Amorós C, et al. Factors predicting poor prognosis in ischemic colitis. World $J$ Gastroenterol 2006;12:4875-8.

16. Higgins PD, Davis KJ, Laine L. Systematic review: the epidemiology of ischaemic colitis. Aliment Pharmacol Ther 2004;19:729-38.

17. Longstreth GF. Definition and classification of irritable bowel syndrome: 
current consensus and controversies. Gastroenterol Clin North Am 2005;34:173-87.

18. Whitehead WE, Palsson O, Jones KR. Systematic review of the comorbidity or irritable bowel syndrome with other disorders: what are the causes and implications? Gastroenterology 2002;122:1140-56.

19. Longstreth GF, Thompson WG, Chey WD, Houghton LA, Mearin F, Spiller RC. Functional bowel disorders. Gastroenterology 2006;130:1480-91.

20. MacDonald PH. Ischaemic colitis. Best Pract Res Clin Gastroenterol
2002;16:51-61.

21. Habu Y, Tahashi Y, Kiyota K, Matsumura K, Hirota M, Inokuchi H, et al. Reevaluation of clinical features of ischemic colitis. Analysis of 68 consecutive cases diagnosed by early colonoscopy. Scand $J$ Gastroenterol 1996;31:881-6.

22. Park CJ, Jang MK, Shin WG, Kim HS, Kim HS, Lee KS, et al. Can we predict the development of ischemic colitis among patients with lower abdominal pain? Dis Colon Rectum 2007;502:232-8. 